\title{
Imagem corporal em relação a frequência alimentar de adolescentes do sexo feminino
}

\author{
Valter Paulo Neves Miranda, Núbia de Souza de Morais, Karina Rafaela Ramos, Joice Ermelinda \\ Cecílio da Silva, Silvia Eloiza Priore
}

\begin{abstract}
Resumo
A adolescência é uma fase da vida que ocorrem mudanças que influenciam todo o processo de avaliação da aparência física. A imagem corporal representa como o indivíduo se sente, se comporta e se percebe em relação as suas formas corporais. Adolescentes do sexo feminino apresentam maior preocupação com sua imagem corporal em relação aos meninos, principalmente maior insatisfação e distorção causadas pelo desejo em se ter um corpo magro. Avaliar a imagem corporal em relação a frequência alimentar de adolescentes do sexo feminino. Estudo transversal com 274 adolescentes do sexo feminino, entre 14 e 19 anos, residentes no município de Viçosa, MG. O estudo é vinculado ao projeto de doutorado aprovado pelo Comitê de Ética em Pesquisa com Seres Humanos da UFV sob o registro 700.976 em 04/07/2014. A imagem corporal foi avaliada pela Escala de Silhuetas e pelo Questionário de Imagem Corporal (Body Shape Questionnaire - BSQ). Foram aferidos peso e estatura, para posterior cálculo do Índice de Massa Corporal (IMC), sendo este classificado por meio de percentis, utilizando-se as curvas de IMC/idade da WHO (2007). O percentual de gordura corporal (\%GC) foi aferido utilizando-se a balança Tanita BC-543® e classificado segundo os pontos de corte de Willians et al. (1992). O Perímetro da Cintura (PC) foi aferido e utilizado para o cálculo da Relação Cintura-Estatura (RCE). Foram aferidas as dobras cutâneas tricipital, bicipital, suprailíaca e subescapular, através das técnicas da WHO (1995). Para avaliar o consumo alimentar foi utilizado o Questionário de frequência alimentar (QFA) simplificado e dividido nos grupos alimentares. A média de idade entre as adolescentes foi de 15,6 $( \pm 1,26)$ anos. Observou-se que, durante os sete dias analisados, mais adolescentes consumiam doces e açúcares $(30,6 \%)$ que frutas ou sucos naturais $(25,4 \%)$. Verificou-se que a média do número de refeições/dia no fim de semana $(3,98 \pm 1,02)$ foi menor que durante a semana $(4,06 \pm 0,85)$. Pela avaliação da Escala de Silhuetas, $50 \%$ das meninas se apresentaram insatisfeitas com a imagem corporal. De acordo com o BSQ, 45,5\% das adolescentes apresentou algum grau de insatisfação com a imagem corporal. A figura da silhueta mais escolhida como a ideal foi a de número 03 (23,5\%), que representa um IMC de 17,5 $\mathrm{kg} / \mathrm{m}^{2}$, que seria classificado como baixo peso. Também foi verificado que a média do número de refeições total, durante a semana e no final de semana teve relação e associação com a insatisfação corporal, ou seja, quanto menor o número de refeições relatada pelas adolescentes maior a insatisfação corporal $(\mathrm{p}<0,05)$. Isso mostra que as meninas mais insatisfeitas faziam maior restrição alimentar. A insatisfação corporal e o desejo por um corpo magro foi evidente nas adolescentes. As meninas mais insatisfeitas restringiram mais o número de refeições em relação àquelas mais satisfeitas com sua imagem corporal. É importante a realização de estudos que avaliem diferentes variáveis da composição corporal e os hábitos alimentares da população adolescente para se verificar os diferentes fatores que podem estar relacionados com a avaliação imagem corporal.
\end{abstract}

Descritores: Adolescentes; Imagem Corporal; Consumo Alimentar. 